\title{
IRS1 G972R polymorphism and type 2 diabetes: a paradigm for the difficult ascertainment of the contribution to disease susceptibility of 'low-frequency-low-risk' variants
}

\author{
E. Morini $\cdot$ S. Prudente $\cdot$ E. Succurro $\cdot$ M. Chandalia $\cdot$ Y.-Y. Zhang $\cdot$ S. Mammarella $\cdot$ \\ F. Pellegrini - C. Powers • V. Proto • B. Dallapiccola • A. Cama - G. Sesti • N. Abate • \\ A. Doria $\cdot$ V. Trischitta
}

Received: 23 March 2009/Accepted: 28 May 2009/Published online: 26 June 2009

(C) Springer-Verlag 2009

\begin{abstract}
Aims/hypothesis The aim of the study was to determine the association between IRS1 G972R polymorphism and type 2 diabetes; published data concerning this association have been conflicting. To obtain further insight into this topic, we performed a meta-analysis of all available case-control studies. Methods We performed a meta-analysis of 32 studies (12,076 cases and 11,285 controls).

Results The relatively infrequent R972 variant was not significantly associated with type 2 diabetes (OR 1.09, 95\% CI $0.96-1.23, p=0.184$ under a dominant model). Some evidence of heterogeneity was observed across studies $(p=0.1)$. In the 14 studies $(9,713$ individuals) in which the mean age at type 2 diabetes diagnosis was available, this variable explained $52 \%$ of the heterogeneity $(p=0.03)$. When these studies were subdivided into tertiles of mean age at diagnosis, the OR for diabetes was 1.48 (95\% CI 1.17-1.87),
\end{abstract}

Electronic supplementary material The online version of this article (doi:10.1007/s00125-009-1426-4) contains supplementary material, which is available to authorised users.

E. Morini $\cdot$ S. Prudente $\cdot$ V. Proto $\cdot$ B. Dallapiccola $\cdot$

V. Trischitta $(\triangle)$

IRCCS, Casa Sollievo della Sofferenza-Mendel Institute,

Viale Regina Margherita 261,

Postal Code 00198 Rome, Italy

e-mail: vincenzo.trischitta@uniroma1.it

E. Succurro $\cdot$ G. Sesti

Department of Experimental and Clinical Medicine,

University Magna Graecia,

Catanzaro, Italy

M. Chandalia $\cdot$ N. Abate

Division of Endocrinology and Metabolism,

University of Texas Medical Branch,

Galveston, TX, USA
1.22 (95\% CI 0.97-1.53) and 0.88 (95\% CI 0.68-1.13) in the youngest, intermediate and oldest tertile, respectively ( $p=0.0022$ for trend of ORs).

Conclusions/interpretation Our findings illustrate the difficulties of ascertaining the contribution of 'lowfrequency-low-risk' variants to type 2 diabetes susceptibility. In the specific context of the R972 variant, $\sim 200,000$ study individuals would be needed to have $80 \%$ power to identify a $9 \%$ increase in diabetes risk at a genome-wide significance level. Under these circumstances, a strategy aimed at improving outcome definition and decreasing its heterogeneity may critically enhance our ability to detect genetic effects, thereby decreasing the required sample size. Our data suggest that focusing on early-onset diabetes, which is characterised by a stronger genetic background, may be part of such a strategy.

Y.-Y. Zhang $\cdot$ C. Powers $\cdot$ A. Doria

Research Division, Joslin Diabetes Center,

Boston, MA, USA

Y.-Y. Zhang $\cdot$ A. Doria

Department of Medicine, Harvard Medical School,

Boston, MA, USA

S. Mammarella $\cdot$ A. Cama

Department of Oncology and Neurosciences,

University G. D’Annunzio,

Chieti, Italy 
Keywords Age at type 2 diabetes diagnosis . Genetics of type 2 diabetes · Insulin signalling . Insulin secretion $\cdot$ Meta-analysis

\begin{tabular}{|c|c|}
\hline \multicolumn{2}{|c|}{ Abbreviations } \\
\hline GENIUS & $\begin{array}{l}\text { Genetics of type } 2 \text { diabetes in Italy } \\
\text { and the United States }\end{array}$ \\
\hline GWAS & Genome-wide association studies \\
\hline HWE & Hardy-Weinberg equilibrium \\
\hline MAF & Minor allele frequency \\
\hline SNP & Single nucleotide polymorphism \\
\hline
\end{tabular}

\section{Introduction}

Despite the recent advances resulting from genome-wide association studies (GWAS), most of the genetic factors contributing to type 2 diabetes remain undetermined [1]. IRS-1 is an important member of a protein family phosphorylated by the insulin receptor upon its binding with insulin [2]. Tissue-specific knockout mice have shown that IRS-1 is necessary for in vivo insulin action and secretion [2]. A relatively infrequent glycine to arginine substitution at position 972 of IRS1 (G972R or rs1801278, minor allele frequency [MAF] ranging from 0.02 to 0.10 in the four different population samples available from HapMap) has been extensively investigated as a determinant of type 2 diabetes susceptibility. In vitro studies have shown that the R972 allele results in a loss of IRS-1 function, which impairs insulin signalling in several target tissues, including skeletal muscle, fat and pancreatic beta cells [2-4]. In vivo studies have reported an association between IRS1 R972 variant and both insulin resistance

\footnotetext{
$\overline{\text { S. Mammarella }} \cdot$ A. Cama

Center of Excellence on Aging,

G. D’Annunzio University Foundation,

Chieti, Italy

F. Pellegrini

Unit of Biostatistics, IRCCS Casa Sollievo della Sofferenza,

San Giovanni Rotondo, Italy

F. Pellegrini

Department of Clinical Pharmacology and Epidemiology,

Consorzio Mario Negri Sud,

Santa Maria Imbaro, Italy

V. Trischitta

Department of Medical Pathophysiology, Sapienza University, Rome, Italy

V. Trischitta

Research Unit of Diabetes and Endocrine Diseases,

IRCCS Casa Sollievo della Sofferenza,

San Giovanni Rotondo, Italy
}

$[2,5]$ and reduced insulin secretion $[2,6]$. The deleterious role of the R972 variant on in vivo insulin action and glucose homeostasis has been recently confirmed by studies in transgenic mice [7]. In spite of such strong evidence for a functional role, the data concerning the association of this variant with type 2 diabetes have been, thus far, conflicting. An initial meta-analyses of 27 studies indicated that R972 carriers had a $25 \%$ increase in type 2 diabetes risk [8], but subsequent large case-control studies have failed to replicate this association (in Table 1 of the Electronic supplementary material [ESM] see Zeggini et al. [9], Florez et al. [10] and van Dam et al. [11]). Unfortunately, neither the G972R variant nor good proxies in linkage disequilibrium with it (i.e. $r^{2}>0.5$ ) were included in the publicly available GWAS meta-analysis DIAGRAM [12].

To obtain further insight into the role of R972 in type 2 diabetes, we performed an updated meta-analysis of all case-control studies available to date (ESM Table 1). BMI and age at diabetes onset were analysed as covariates in meta-regression.

\section{Methods}

Study design All case-control studies reported in previous meta-analyses [8] and all papers found in the PubMed database as of January 2009 by using 'insulin receptor substrate-1', 'IRS-1', 'Gly972Arg', 'G972R', 'diabetes', 'variant', 'polymorphism' and 'genotype' as keywords, were analysed. In addition, we included five unpublished case-control studies in which all study participants were self-reported whites: four sets from the Genetics of Type 2 Diabetes in Italy and the United States (GENIUS T2D) Consortium [13] (N. Abate, A. Doria, G. Sesti and V. Trischitta) and one set recruited in Chieti, Italy (ESM Table 1; Cama A. sample) (S. Mammarella and A. Cama). Three of the published studies were excluded because they were subsets of these unpublished sets: in ESM Table 1 see Sigal et al. [14] of the GENIUS Boston sample, Mammarella et al. [15] and Esposito et al. [16] of the Cama A. sample.

Study individuals in unpublished samples Controls in all unpublished samples were non-diabetic individuals with fasting plasma glucose $<6.9 \mathrm{mmol} / \mathrm{l}$ and absence of drug treatment known to affect glucose metabolism. Cases were patients with type 2 diabetes defined according to the 2003 American Diabetes Association criteria.

DNA extraction and genotyping DNA from the unpublished sets was extracted from whole blood by standard methods. Genotyping details are described in the methods section of the ESM. 
Study

Almind et al. (1993) [25]

Hager et al. (1993) [26]

Imai et al. (1994) [27]

Shimokawa et al. (1994) [28]

Hitman et al. (1995) [29]

Hitman et al. (1995) [29]

Mori et al. (1995) [30]

Chuang et al. (1996) [31]

Ura et al. (1997) [32]

Zhang et al. (1996) [33]

Panz et al. (1997) [34]

Panz et al. (1997) [34]

Lepetre et al. (1998) [35]

Yamada et al. (1998) [36]

Ito et al. (1999) [37]

Hart et al. (1999) [38]

Hart et al. (1999) [38]

Lei et al. (1999) [39]

Celi et al. (2000) [40]

Celi et al. (2000) [40]

Rosskopf et al. (2000) [41]

Zeggini et al. (2004) [9]

Zeggini et al. (2004) [9]

Florez et al. (2004) [10]

Florez et al. (2004) [10]

Florez et al. (2004) [10]

van Dam et al. (2004) [11]

Orkunoglu Suer et al. (2005) [42]

GENIUS from Boston (unpublished)

GENIUS from Dallas (unpublished)

GENIUS from SGR (unpublished)

Cama A. (unpublished)

Summary OR
Sample size

$$
16
$$

363
63

63
375

221

82

283
171

171

170

372

30

30
99

1,106

364

361

274

1,313

58

120

1,282

1,287

1,287
2,429

1,999

4,360

621

186

1,330

472

1,892

581

23,361
OR

\subsection{0}

1.69

2.04

0.78

2.07

1.05

1.73

0.92

1.18

0.59

4.75

2.25

0.60

1.46

0.62

1.32

0.95

1.05

0.55

1.89

1.82

0.96

1.24

0.79

1.10

1.00

0.81

1.26

1.37

1.14

1.10

0.73

1.09
Lower limit Upper limit

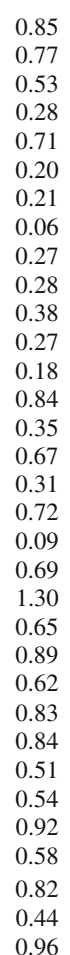

0.85
0.77

0.53

0.28

0.71

0.20

0.06
0.27

0.28

0.38

0.27

0.84

67

0.31

0.72

69

1.30

0.89

0.62

0.83

0.84

0.51

.92

0.58

82

0.96

$\begin{array}{rr} & \\ .85 & 12.10 \\ .77 & 3.72 \\ 53 & 7.83 \\ .28 & 2.20 \\ .71 & 6.02 \\ 20 & 5.56 \\ .21 & 13.99 \\ .06 & 14.96 \\ .27 & 5.09 \\ .28 & 1.22 \\ 38 & 60.14 \\ .27 & 18.93 \\ .18 & 1.97 \\ .84 & 2.56 \\ .35 & 1.10 \\ .67 & 2.59 \\ .31 & 2.89 \\ 0.72 & 1.55 \\ 0.09 & 3.58 \\ 0.69 & 5.20 \\ .30 & 2.56 \\ 0.65 & 1.40 \\ .89 & 1.71 \\ 0.62 & 1.00 \\ 0.83 & 1.46 \\ .84 & 1.20 \\ 0.51 & 1.27 \\ .54 & 2.91 \\ 0.92 & 2.03 \\ 0.58 & 2.26 \\ 02 & 1.47 \\ .44 & 1.22 \\ .96 & 1.23 \\ & \end{array}$

$p$ value

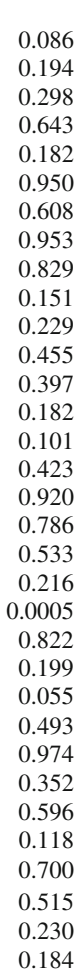

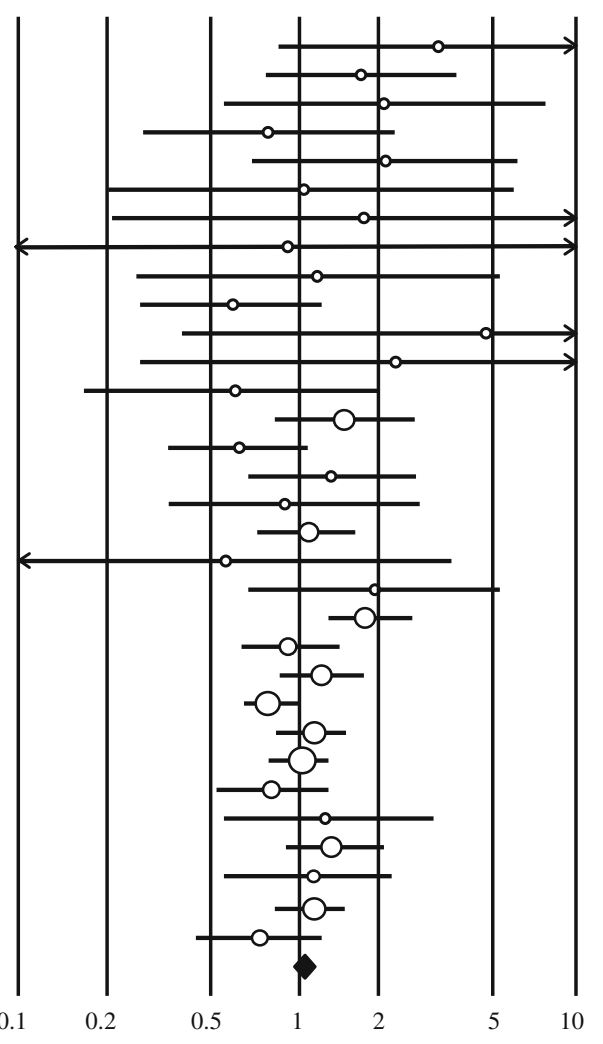

OR and $95 \%$ CI

GG

$\mathrm{GR}+\mathrm{RR}$
Fig. 1 Meta-analysis of 30 case-control studies. The cumulative effect of 32 published (ordered by publication date) and unpublished studies on the association between IRS1 G972R polymorphism and type 2 diabetes was tested by a random-effects model. A borderline significant heterogeneity was observed across studies (Cochran's
$Q$ test $p=0.1$ ). ORs and $95 \%$ CIs for dominant genetic model are shown. Sizes of OR symbols are proportional to the study sample size. 95\% CIs have arrowheads when they exceed the figure limits. SGR, San Giovanni Rotondo, Italy

controls were considered in the meta-analysis (ESM Table 1). Given the small number of RR individuals (i.e. homozygous for the R972 variant) in 12 studies and their absence in the other 20 (a finding that could seriously bias the results of both additive and recessive models), we investigated only the dominant model, by comparing GR+RR (these latter when available) with GG individuals. Figure 1 shows the individual results from the 32 casecontrol studies, along with those of the meta-analysis, which included 12,076 cases and 11,285 controls. As for any meta-analysis performed on published genetic data, we cannot exclude the possibility that some sample overlap has occurred; however, by carefully reading the description of samples analysed in each study, this seems to be an unlikely event. No evidence of publication bias was observed $(p=0.27)$. The ORs for association between R972 and type 2 diabetes ranged from 0.55 to 4.75 . In the meta-analysis, the R972 variant did not show a significant association with 
Fig. 2 Relationship between OR of type 2 diabetes and age at type 2 diabetes diagnosis in the 14 studies for which this information was available $(n=9,713$ individuals). a Meta-regression of mean age at diagnosis of type 2 diabetes and $\log$ OR for type 2 diabetes of the R972 variant according to a dominant genetic model. Sizes of OR symbols are proportional to the study sample size. There was a significant correlation $(p=0.03)$ explaining $52 \%$ of betweenstudy heterogeneity. b Summary ORs of type 2 diabetes according to tertiles of age at type 2 diabetes diagnosis. The ranges of age at type 2 diabetes diagnosis were $39-44.9$ years (five studies, $n=3,234$ individuals), 45-50.9 years (five studies, $n=4,228$ individuals) and $51-$ 58 years (four studies, $n=2,251$ individuals) in tertile 1, 2 and 3, respectively

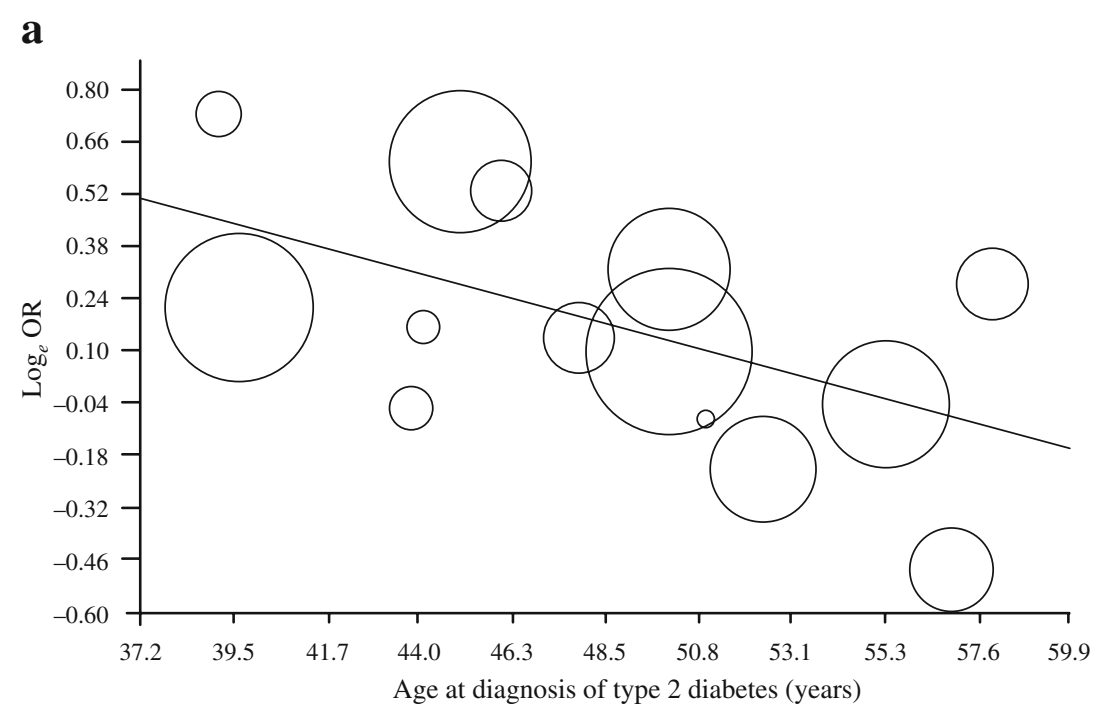

b

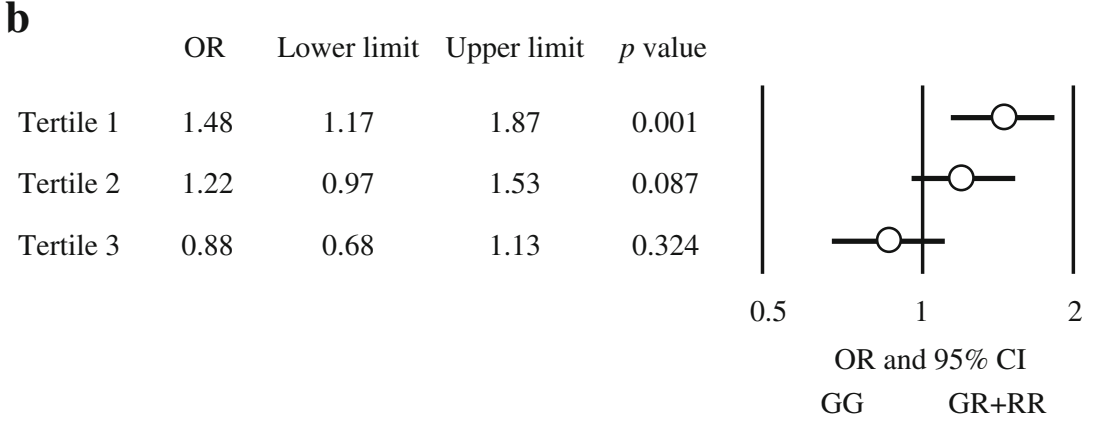

type 2 diabetes (OR 1.09, 95\% CI 0.96-1.23, $p=0.184$ ). Some evidence of heterogeneity was observed across studies (Cochran's $Q$ test $p=0.1$ ). In a meta-regression analysis, neither the mean BMI of cases nor that of controls (available in 23 studies corresponding to 20,114 individuals) significantly explained such heterogeneity $(p=0.58$ and $p=0.84$, respectively). Similar data were obtained when analyses were carried after stratifying for BMI status (i.e. $<30 \mathrm{~kg} / \mathrm{m}^{2}$ or $\left.\geq 30 \mathrm{~kg} / \mathrm{m}^{2}\right) \quad(p=0.77)$. Also no effect of ethnicity (i.e. either white [19,075 individuals from 20 studies], Asian [2,699 individuals from eight studies] or other [1,587 individuals from four studies]) was observed $(p=0.91)$. Also, when only studies whose sample size was $>500$ individuals were analysed, a similar OR to that obtained in the whole meta-analysis was observed (OR 1.08, 95\% CI 0.93-1.24). By contrast, the mean age at type 2 diabetes diagnosis (available in 14 studies corresponding to 9,713 individuals) was significantly correlated with the magnitude of the genetic effect, explaining $52 \%$ of the heterogeneity $(p=0.03)$ (Fig. 2a). When these studies were subdivided into tertiles of mean age at diagnosis, the summary OR of type 2 diabetes was 1.48 (95\% CI 1.17-1.87) for studies in the youngest tertile (39-44.9 years), 1.22 (95\% CI $0.97-1.53$ ) for studies in the intermediate tertile (45-50.9 years), and
0.88 (95\% CI $0.68-1.13)$ for studies in the oldest tertile (5158 years) (Fig. 2b). The standard $p$ value for the decreasing trend of ORs with increasing mean age at diagnosis was 0.0022 and the permutation $p$ value was 0.014 .

\section{Discussion}

Our findings illustrate the difficulties of ascertaining contributions to type 2 diabetes susceptibility by 'lowfrequency-low-risk' variants. Despite the fact that this study included more than 23,000 individuals, the power to identify a $9 \%$ increase in type 2 diabetes risk associated with a variant having 0.06 frequency was only $58 \%$ at nominal significance levels $(\alpha=0.05)$ and virtually zero at genome-wide significance levels $\left(\alpha=5 \times 10^{-8}\right)$. One can estimate that a total of $\sim 40,000$ and $\sim 200,000$ individuals would have been required to have $80 \%$ power at $\alpha=0.05$ and $\left(\alpha=5 \times 10^{-8}\right)$, respectively. Under these circumstances, improving the outcome definition and decreasing its heterogeneity may have critical effects on our ability to identify genetic effects.

In our meta-analysis, studies in which the mean age at type 2 diabetes diagnosis was $<45$ years showed an OR for 
type 2 diabetes of 1.48, an effect size that a sample of 'only' $\sim 8,500$ individuals would have $80 \%$ power to detect with genome-wide significance. Similar data, indicating a stronger effect on early abnormality of glucose homeostasis, were recently reported for TCF7L2 [20] and for TRIB3 [10]. Unfortunately, no data on the combined effect of several single-nucleotide polymorphisms (SNPs) that are singly associated with early glucose abnormalities are so far available. Overall, focusing on forms of diabetes diagnosed relatively early in life, which are known to have a stronger genetic component $[21,22]$, may be a useful strategy to facilitate the identification of SNPs associated with type 2 diabetes that are otherwise difficult to find, either because of their moderate effect or because of their low allelic frequency, or because of both factors, as in the case of IRS1 G972R. The usefulness of this approach may also extend to truly rare variants (MAF $<0.01$ ), such as those that are believed to underlie the linkage peaks that are not explained by the common variants identified through GWAS. Indeed, in the linkage screen of the Diabetes UK Warren 2 sib pair collection, all seven linkage signals that were identified were stronger in families with an average age at diagnosis $<55$ years than in the families diagnosed at an older age [23].

In conclusion, the study of early-onset forms is emerging as a critical tool to reach the 'high-hanging' fruits of type 2 diabetes genetics and mirrors the approach taken with other complex disorders such as coronary artery disease [24]. Thus, both adequately powered new studies specifically targeted to early-onset cases and further analyses of available GWAS data after stratification by age at onset are needed.

Acknowledgements This work was partly supported by the Italian Ministry of Health (Ricerca Corrente 2007 to S. Prudente and 2009 to S. Prudente and V. Trischitta) and by the NIH (grants HL073168, DK055523 and DK036836 to A. Doria and the Genetics Core of the Diabetes and Endocrinology Research Center at the Joslin Diabetes Center).

Duality of interest The authors declare that there is no duality of interest associated with this manuscript.

\section{References}

1. Doria A, Patti ME, Kahn CR (2008) The emerging genetic architecture of type 2 diabetes. Cell Metab 8:186-200

2. Sesti G, Federici M, Hribal ML, Lauro D, Sbraccia P, Lauro R (2001) Defects of the insulin receptor substrate (IRS) system in human metabolic disorders. FASEB J 15:2099-2111

3. Almind K, Inoue G, Pedersen O, Kahn CR (1996) A common amino acid polymorphism in insulin receptor substrate- 1 causes impaired insulin signaling. Evidence from transfection studies. J Clin Invest 97:2569-2575
4. Marchetti P, Lupi R, Federici M et al (2002) Insulin secretory function is impaired in isolated human islets carrying the Gly9723Arg IRS-1 polymorphism. Diabetes 51:1419-1424

5. Clausen JO, Hansen T, Bjørbaek C et al (1995) Insulin resistance: interactions between obesity and a common variant of insulin receptor substrate-1. Lancet 346:397-402

6. Stumvoll M, Fritsche A, Volk A et al (2001) The Gly972Arg polymorphism in the insulin receptor substrate-1 gene contributes to the variation in insulin secretion in normal glucose-tolerant humans. Diabetes 50:882-885

7. Hribal ML, Tornei F, Pujol A et al (2008) Transgenic mice overexpressing human G972R IRS-1 show impaired insulin action and insulin secretion. J Cell Mol Med 12:2096-2106

8. Jellema A, Zeegers MP, Feskens EJ, Dagnelie PC, Mensink RP (2003) Gly972Arg variant in the insulin receptor substrate-1 gene and association with type 2 diabetes: a meta-analysis of 27 studies. Diabetologia 46:990-995

9. Zeggini E, Parkinson J, Halford S et al (2004) Association studies of insulin receptor substrate 1 gene (IRS1) variants in type 2 diabetes samples enriched for family history and early age of onset. Diabetes 53:3319-3322

10. Florez JC, Sjögren M, Burtt N et al (2004) Association testing in 9,000 people fails to confirm the association of the insulin receptor substrate-1 G972R polymorphism with type 2 diabetes. Diabetes 53:3313-3318

11. van Dam RM, Hoebee B, Seidell JC, Schaap MM, Blaak EE, Feskens EJ (2004) The insulin receptor substrate-1 Gly972Arg polymorphism is not associated with Type 2 diabetes mellitus in two population-based studies. Diabet Med 21:752-758

12. Zeggini E, Scott LJ, Saxena R et al (2008) Meta-analysis of genome-wide association data and large-scale replication identifies additional susceptibility loci for type 2 diabetes. Nat Genet 40:638-645

13. Prudente S, Scarpelli D, Chandalia M et al (2009) The TRIB3 Q84R polymorphism and risk of early-onset type 2 diabetes. J Clin Endocrinol Metab 94:190-196

14. Sigal RJ, Doria A, Warram JH, Krolewski AS (1996) Codon 972 polymorphism in the insulin receptor substrate-1 gene, obesity, and risk of noninsulin-dependent diabetes mellitus. J Clin Endocrinol Metab 81:1657-1659

15. Mammarella S, Esposito DL, Creati B et al (1996) Mutational analysis of the insulin receptor substrate-1 in noninsulin dependent diabetes. Diabetologia 39(Suppl 1):A75 Abstract

16. Esposito DL, Li Y, Vanni C et al (2003) A novel T608R missense mutation in insulin receptor substrate-1 identified in a subject with type 2 diabetes impairs metabolic insulin signaling. J Clin Endocrinol Metab 88:1468-1475

17. Macaskill P, Walter SD, Irwig L (2001) A comparison of methods to detect publication bias in meta-analysis. Stat Med 20:641-654

18. van Houwelingen HC, Arends LR, Stijnen T (2002) Advanced methods in meta-analysis: multivariate approach and metaregression. Stat Med 21:589-624

19. Higgins JP, Thompson SG (2004) Controlling the risk of spurious findings from meta-regression. Stat Med 23:1663-1682

20. Körner A, Berndt J, Stumvoll M, Kiess W, Kovacs P (2007) TCF7L2 gene polymorphisms confer an increased risk for early impairment of glucose metabolism and increased height in obese children. J Clin Endocrinol Metab 92:1956-1960

21. Weijnen CF, Rich SS, Meigs JB, Krolewski AS, Warram JH (2002) Risk of diabetes in siblings of index cases with type 2 diabetes: implications for genetic studies. Diabet Med 19:41-50

22. Mitchell BD, Kammerer CM, Reinhart LJ, Stern MP (1994) NIDDM in Mexican-American families. Heterogeneity by age of onset. Diabetes Care 17:567-573

23. Frayling TM, Wiltshire S, Hitman GA et al (2003) Young-onset type 2 diabetes families are the major contributors to genetic loci 
in the Diabetes UK Warren 2 genome scan and identify putative novel loci on chromosomes 8q21, 21q22, and 22q11. Diabetes 52:1857-1863

24. Myocardial Infarction Genetics Consortium, Kathiresan S, Voight BF et al (2009) Genome-wide association of early-onset myocardial infarction with single nucleotide polymorphisms and copy number variants. Nat Genet 41:334-341

25. Almind K, Bjørbaek C, Vestergaard H, Hansen T, Echwald S, Pedersen O (1993) Amino acid polymorphisms of insulin receptor substrate-1 in non-insulin-dependent diabetes mellitus. Lancet 342:828-832

26. Hager J, Zouali H, Velho G, Froguel P (1993) Insulin receptor substrate (IRS-1) gene polymorphisms in French NIDDM families. Lancet 342:1430

27. Imai Y, Fusco A, Suzuki Y et al (1994) Variant sequences of insulin receptor substrate-1 in patients with noninsulin-dependent diabetes mellitus. J Clin Endocrinol Metab 79:1655-1658

28. Shimokawa K, Kadowaki H, Sakura H et al (1994) Molecular scanning of the glycogen synthase and insulin receptor substrate-1 genes in Japanese subjects with non-insulin-dependent diabetes mellitus. Biochem Biophys Res Commun 202:463-469

29. Hitman GA, Hawrami K, McCarthy MI et al (1995) Insulin receptor substrate-1 gene mutations in NIDDM; implications for the study of polygenic disease. Diabetologia 38:481-486

30. Mori H, Hashiramoto M, Kishimoto M, Kasuga M (1995) Amino acid polymorphisms of the insulin receptor substrate-1 in Japanese noninsulin-dependent diabetes mellitus. J Clin Endocrinol Metab $80: 2822-2826$

31. Chuang LM, Lai CS, Yeh JI, Wu HP, Tai TY, Lin BJ (1996) No association between the Gly971Arg variant of the insulin receptor substrate 1 gene and NIDDM in the Taiwanese population. Diabetes Care 19:446-449

32. Ura S, Araki E, Kishikawa H et al (1996) Molecular scanning of the insulin receptor substrate-1 (IRS-1) gene in Japanese patients with NIDDM: identification of five novel polymorphisms. Diabetologia 39:600-608

33. Zhang Y, Stratton IM, Warren-Perry MG, Orho M, Groop L, Turner RC (1996) UKPDS 19: heterogeneity in NIDDM: separate contributions of IRS-1 and beta3-adrenergic-receptor mutations to insulin resistance and obesity respectively with no evidence for glycogen synthase gene mutations. Diabetologia 39:1505-1511

34. Panz VR, Raal FJ, O'Rahilly S, Kedda MA, Joffe BI (1997) Insulin receptor substrate-1 gene variants in lipoatrophic diabetes mellitus and non-insulin-dependent diabetes mellitus: a study of South African black and white subjects. Hum Genet 101:118-119

35. Lepretre F, Vionnet N, Budhan S et al (1998) Genetic studies of polymorphisms in ten non-insulin-dependent diabetes mellitus candidate genes in Tamil Indians from Pondicherry. Diabetes Metab 24:244-250

36. Yamada K, Yuan X, Ishiyama S et al (1998) Codon 972 polymorphism of the insulin receptor substrate-1 gene in impaired glucose tolerance and late-onset NIDDM. Diabetes Care 21:753-756

37. Ito K, Katsuki A, Furuta M et al (1999) Insulin sensitivity is not affected by mutation of codon 972 of the human IRS-1 gene. Horm Res 52:230-234

38. Hart LM, Stolk RP, Dekker JM et al (1999) Prevalence of variants in candidate genes for type 2 diabetes mellitus in the Netherlands: the Rotterdam study and the Hoorn study. J Clin Endocrinol Metab 84:1002-1006

39. Lei HH, Coresh J, Shuldiner AR, Boerwinkle E, Brancati FL (1999) Variants of the insulin receptor substrate-1 and fatty acid binding protein 2 genes and the risk of type 2 diabetes, obesity, and hyperinsulinemia in African-Americans: the atherosclerosis risk in communities study. Diabetes 48:1868-1872

40. Celi FS, Negri C, Tanner K et al (2000) Molecular scanning for mutations in the insulin receptor substrate-1 (IRS-1) gene in Mexican Americans with type 2 diabetes mellitus. Diabetes Metab Res Rev 16:370-377

41. Rosskopf D, Frey U, Eckhardt S et al (2000) Interaction of the G protein beta 3 subunit T825 allele and the IRS-1 Arg972 variant in type 2 diabetes. Eur J Med Res 5:484-490

42. Orkunoglu Suer FE, Mergen H, Bolu E, Ozata M (2005) Molecular scanning for mutations in the insulin receptor substrate-1 (IRS-1) gene in Turkish with type 2 diabetes mellitus. Endocr J 52:593-598 